\title{
Application and Research of Carbon Footprint Calculation in Cotton Mill
}

\author{
SUN Meirong ${ }^{1, a}$, WEI Mengyuan ${ }^{1, b}$, LIU Fang ${ }^{1, c}$, XUE Wenliang $^{2, d}$ \\ ${ }^{1}$ Shanghai Entry-Exit Inspection and Quarantine Bureau, Shanghai, China \\ ${ }^{2}$ Donghua University, Shanghai, China \\ âsunmr@shciq.gov.cn, ${ }^{b}$ weimy@shciq.gov.cn, ${ }^{\text {lliufang@shciq.gov.cn, }{ }^{d} x w 1 @ d h u . e d u . c n}$
}

Keywords: Carbon Footprint; Cotton Mill; Power Consumption; Carbon Emissions; Energy-saving Abstract. Carbon footprint calculation methods and its application in cotton mill were studied. Overall idea of carbon footprint calculation in cotton mill as well as power consumption of each equipment in production was analyzed. It is pointed out that carbon emissions can be obtained by the indirect method of calculating power consumption. It is considered that it is feasible to calculate indirectly carbon emissions by power consumption. Carbon emissions of each process in mill can be got by calculating carbon footprint, higher carbon emissions process can be monitored, energy-saving space can be got.

\section{Introduction}

Today, as economy is developing fast, the demand of human for energy is increasing rapidly. The application of the large number of fossil energy will inevitably lead to the greenhouse gas concentrations rising rapidly, leading to global warming. Therefore, to reduce greenhouse gas emissions and to reduce global warming has become the consensus reached for all mankind. Carbon footprint is often called "carbon consumption" "[1] The carbon footprint calculation as an important tool to measure the heavy volume of the carbon emissions in product cycle has been applied to various industries. Cotton spinning industry is one of China's energy-intensive industries. To determine their products' carbon footprint is the first step to reduce carbon emissions behavior. In this paper, the cotton mills for the practice of object , we put carbon footprint calculation method and its application into line analysis for providing the enterprise energy saving methods and ideas, and then provide a reference for the entire industry to improve carbon saving measures.

\section{Calculation and Analysis of Carbon Footprint in Cotton Mill}

First carbon footprint is on the basis of the ecological footprint concept ${ }^{[2-3]}$ in Britain ${ }^{[4-5]}$. Most of the studies used to characterize the carbon emissions. The existing method of LCA (life cycle analysis) ${ }^{[6-7]}$ can calculate the product-related greenhouse gas emissions ${ }^{[8-9]}$. However, the processing of cotton products mainly use electricity as power. In the whole process there are no direct greenhouse gas emissions, only indirect carbon emissions, that is, the electricity consumption. Therefore, to calculate the carbon footprint in processing of cotton products, we must first analyze the energy consumption of the product during processing of the cotton spinning.

\section{Analysis of Energy Consumption in Cotton Mill}

\section{Main engines}

The main engine is the main body of the electrical energy consumption in the cotton spinning. To obtain the yield of a single device in per unit time, and then calculate the number of units of work equipment, then you can find the power consumption of the device in per unit time. Assume that in the spinning mill, the production of C 14.6 tex yarn is $1000 \mathrm{~kg} / \mathrm{h}$, the calculation of the corresponding data is: the number of actual device in the various processes is $N_{i}=1000 / A_{i}\left(A_{i}\right.$ is the production of a single device); the total number of units of the process equipment is $N=\Sigma N_{i}$; the consumption of each process is $W_{i}=P_{i} * T * N_{i}\left(P_{i}\right.$ is the power rating of single piece of equipment in the various processes, $T$ is the running time); then the consumption of the main engines is $W_{z j}=\Sigma W_{i}$. 


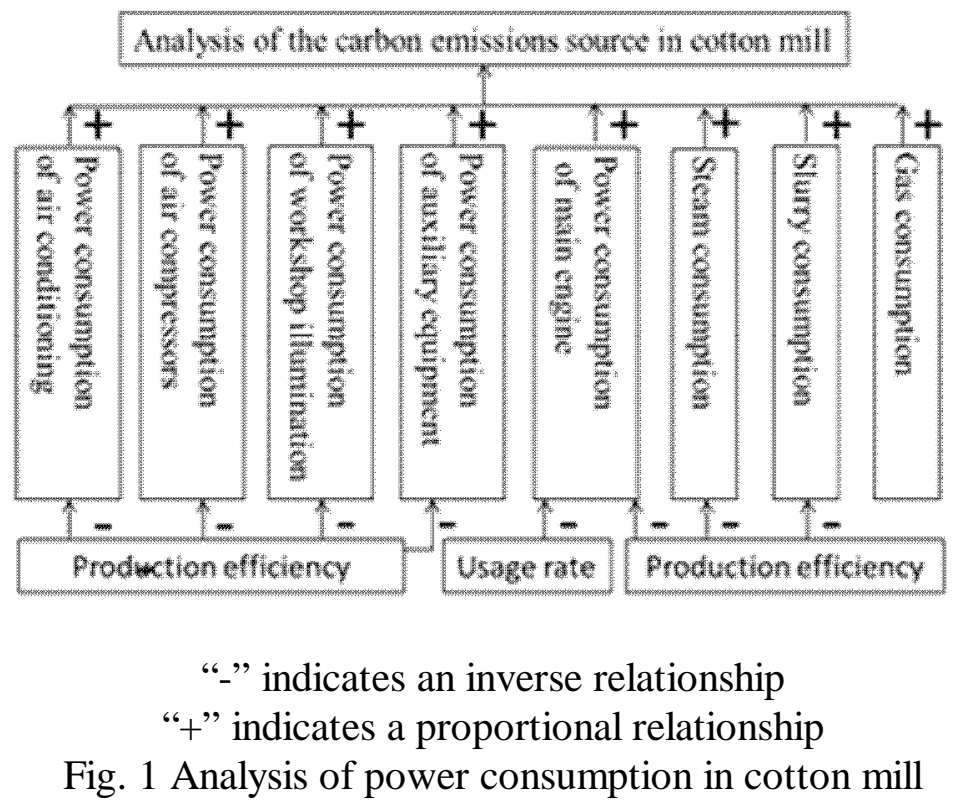

\section{Air-conditioning systems}

Air-conditioning systems include ventilation systems, humidification and heating systems, refrigeration systems and so on. Air-conditioning system is not a constant power load, and its power changes greater, so energy consumption calculation is more complicated. This article selects the direct measurement (see the watt-hour meter), first obtain the power consumption of air conditioning systems within a certain time, and finally average to a single device. The calculation process is as follows: the power consumption per hour of each air-conditioning is $W_{k h}=W_{k} / 24 N$ ( $W_{k}$ is measured by the average daily power consumption of air-conditioning systems, $N$ is the total number of the units of actual operating equipment); the power consumption of air conditioning in each process is $W_{k i}=W_{k h}$ $* N_{i} / I_{i}\left(N_{i}\right.$ is the number of actual air-conditioning units in each process, $I_{i}$ is the efficiency of the air conditioning equipment in each process); the total power consumption of air conditioning systems is $W_{k}=\Sigma W_{k i}$.

\section{Illumination}

The power, number and equipment, and machine number of workshop illumination, determine the size of the illumination power consumption; the equipment indirectly determines the level of illumination power consumption in per unit time. The process of calculation is as follows: the power consumption of per illumination in per hour is $W_{z h}=P_{z} * N_{z} / N\left(P_{z}\right.$ is single illumination power, $N_{z}$ is the number of illumination, $N$ is the total number of actual operating equipments); the consumption of illumination in each process is $W_{z i}=W_{z h} * N_{i} / I_{i}\left(N_{i}\right.$ is the number of actual illumination equipment in various processes, $I_{i}$ is the efficiency of the equipment in each process); the total power consumption of the illumination is $W_{z}=\Sigma W_{z i}$.

\section{Air compressors and auxiliary equipment}

Air compressors and auxiliary equipment are not a constant power load as air conditioning equipment, therefore choose direct measurement (see watt-hour meter) too. First obtain the power consumption within a certain time, and finally average to a single device. The process of calculation is similar to the air conditioning system. 


\section{The Method and Principle of Carbon Footprint Calculation}

In the coal-fired power generation, carbon in the coal is combust and oxidized into carbon dioxide which is put into the atmosphere. According to the chemical formula and molecular weight of carbon combust and oxidized to carbon dioxide, it can be calculated that the carbon dioxide emissions are 3.67 $\mathrm{t}$, when consuming $1 \mathrm{t}$ coal. According to our survey of coal composition of 60 typical coal mines, and researches of the State Bureau of Technical Supervision and other units, the carbon content of the four kinds of coal can be calculated. In accordance with its coal production volume, we weight and average it to draw average national coal carbon content. Carbon in the form of carbon dioxide put into the atmosphere is approximately $0.651 \mathrm{t}$, when $1 \mathrm{t}$ of standard coal is combust. Thus, emissions of carbon dioxide of $1 \mathrm{t}$ of standard coal combustion are $3.67 * 0.651=2.39(\mathrm{t})$.

Energy of unit power consumption $(1 \mathrm{kw} \cdot \mathrm{h})$ is $W_{e}=3.6 * 10^{6} \mathrm{~J}$; heat of $1 \mathrm{~g}$ standard coal is $W_{c}=$ $29306 \mathrm{~J}$, the required standard coal of unit power consumption $(1 \mathrm{kw} \cdot h)$ is $C=W_{e} / W_{c}=123 \mathrm{~g}$; that is, unit power consumption $(1 \mathrm{kw} \cdot h)$ needs to consume $123 \mathrm{~g}$ of coal, emissions of carbon dioxide of unit power consumption $(1 \mathrm{kw} \cdot \mathrm{h})$ is $M_{\mathrm{CO} 2}=1 * 123 * 39=294(\mathrm{~g})$. Therefore, by calculating the power consumption of a single process of the cotton mills, it ultimately can be derived carbon dioxide emissions of a single process.

\section{Applications of Carbon Footprint Calculation}

\section{Application examples}

According to the above calculation of carbon footprint, it can be obtained theoretical power consumption and carbon dioxide emissions of C 18 tex yarn in a spinning factory in Shanghai of a production line in per unit time $(1 \mathrm{~h})$ at per unit mass $(1000 \mathrm{~kg})$, shown in Table 1 .

Table 1 theoretical power consumption and carbon dioxide emissions of $\mathrm{C} 18$ tex yarn

\begin{tabular}{ccc}
\hline Projects & Power consumption $/ \mathrm{kw} \bullet \mathrm{h}$ & Carbon dioxide emissions $/ g$ \\
\hline Main engines & 1440.9 & 423624.6 \\
Air-conditioning systems & 298.4 & 87729.6 \\
Illumination & 35.5 & 10437.0 \\
Air compressors and auxiliary equipment & 81.6 & 23990.4 \\
Total & 1856.4 & 545781.6 \\
\hline
\end{tabular}

In table 1, the main engines power consumption and carbon dioxide emissions include: the cotton opening and cleaning process power consumption is $50 \mathrm{kw} \bullet \mathrm{h}$, the carbon dioxide emissions is 14700 $\mathrm{g}$; the carding power consumption is $143.1 \mathrm{kw} \bullet \mathrm{h}$, the carbon dioxide emissions is $42071.4 \mathrm{~g}$; the crude process power consumption is $128.2 \mathrm{kw} \bullet \mathrm{h}$, the carbon dioxide emissions is $37690.8 \mathrm{~g}$; the spinning process power consumption is $873.2 \mathrm{kw} \bullet \mathrm{h}$, the carbon dioxide emissions is $256720.8 \mathrm{~g}$; the winding process power consumption is $246.4 \mathrm{kw} \bullet \mathrm{h}$, the carbon dioxide emissions is $72441.6 \mathrm{~g}$. In addition, statistical analysis of power consumption and carbon dioxide emissions of the same production line in per unit time $(1 \mathrm{~h})$ at per unit mass $(1000 \mathrm{~kg}) \mathrm{C} 18.2$ tex yarn of the cotton mill got from the watt-hour meter in consecutive six months shows that, the main engines power consumption is $1100.82 \mathrm{kw} \cdot \mathrm{h}$, the carbon dioxide emissions is $323641.08 \mathrm{~g}$; the air-conditioning power consumption is $280.84 \mathrm{kw} \bullet \mathrm{h}$, the carbon dioxide emissions is $82566.96 \mathrm{~g}$; the lighting power consumption is $34.79 \mathrm{kw} \bullet \mathrm{h}$, the carbon dioxide emissions is $10228.26 \mathrm{~g}$; the Air compressors and auxiliary equipment power consumption is $66.96 \mathrm{kw} \bullet \mathrm{h}$, the carbon dioxide emissions is $19686.24 \mathrm{~g}$; the total power consumption is $1483.10 \mathrm{kw} \bullet \mathrm{h}$, the total carbon dioxide emissions is $436031.40 \mathrm{~g}$.

\section{Analysis of application}

The above-mentioned application instance of carbon footprint calculation shows that, results of the carbon footprint calculation and results of the watt-hour meter statistics are in the same order of magnitude. The calculation method of carbon footprint is feasible in the cotton mills. By applying the 
carbon footprint calculation, we can get the energy consumption and carbon dioxide emissions of cotton products in single process. Put the average of a single product of the individual enterprises in the enterprise library on behalf of the industry average, and we can estimate the overall level of industry about carbon footprint. Carbon footprint calculation and analysis of the same product of different processing equipments can provide the basis for the selection of equipment for enterprises from low-carbon angle. According to the carbon footprint calculation of each process, put forward proposals and measures to reduce carbon emissions, and formulate effective programs to reduce carbon emissions. Provide carbon footprint information of the products to consumers through the carbon footprint calculation, so that consumers can get a quantified understanding of the environmental impact of the production, and then guide the decision-making of consumer.

\section{Summary}

The study of carbon footprint calculation method of cotton mill can effectively improve the accuracy of carbon footprint calculation, the standard of the calculation of special statistical data and the reliability of data. The carbon footprint calculation and analysis refined to a single process, lets the cotton spinning industry from a more microscopic point of view monitor the carbon-intensive sectors, and provides a self-test method to accomplish an accounting of carbon emissions of production phase, which seek to the space of saving energy and reducing row. By applying carbon footprint calculation in the cotton mill, it helps the government to formulate a policy of energy saving and emission reduction in the cotton industry, eliminate backward production capacity, improve the efficiency of the implementation of energy saving policies, and provide support for the country to readjust the industrial structure $^{[10]}$. Meanwhile, China's cotton textile industry under the restrictions of domestic textile industry as a whole lower level, carbon footprint calculation and its application are in the lack of the actual model, and need to constantly improve.

\section{References}

[1] International Organization for Standardization (ISO). ISO International Standard 14040: Environmental Management-Life Cycle Assessment-Principles and Framework [M]. Geneva: International Organization for Standardization. (1997)

[2] Royston M. Pollution Prevention Pays. Pergamon Press, London, UK,1979.

[3] World Commission on Environment and Development[WCED].Our Common Future, The Brundtland Report. Oxford University Press,Oxford, UK, 1987.

[4] Information on http://www.un.org/millenniumgoals/.

[5] Information on http://www.uneptie. org/pc/sustain/lcinitiative/home.htm.

[6] Sherif YS, Kolarik WJ. Life Cycle Costing - Concept and Practice, J. OMEGA - The International Journal of Management Science 9(1981):287-296.

[7] Pré.2004.SimaPro 6 LCA software. Amersfoort, The Netherlands Rebitzer G. Enhancing the Application Efficiency of Life Cycle Assessment for Industrial Uses. Ph.D. Thesis, Swiss Federal Institute of Technology Lausanne. (2005).

[8] Rebitzer G, Hunkeler D. Life Cycle Costing in LCM Ambitions, Opportunities, and Limitations, Discussing a Framework, J. Int J LCA 8 (2003):253-256.

[9] Rebitzer G, Seuring S. Methodology and Application of Life Cycle Costing, J. Int J LCA 8 (2003): $110-111$.

[10] Matthews H S , Hendrickson C,Weber C. The importance of carbon footprint estimation boundaries, J. Environmental Science \& Technology.42(2008):5839-5842. 